\title{
Application of new enhanced medium in indirect antiglobulin test by gel method
}

\author{
Ling Sun ${ }^{1}$, Dan $\mathrm{Xu}{ }^{1}$, Buqiang $\mathrm{Wang}^{1}$, Mengge Chen ${ }^{1}$, Daowang $\mathrm{Fan}^{2 *}$ \\ ${ }^{1}$ Jiangsu LIBO Medicine Biotechnology Co.,Ltd., Jiangyin 214400, Jiangsu, China; \\ ${ }^{2}$ Blood Group Lab, Beijing Red Cross Blood Center, Beijing 100088, China.
}

\begin{abstract}
The objective of this study was to explore the efficacy of a new enhanced medium in indirect antiglobulin test by optimized gel method. Anti-IgG $+\mathrm{C}_{3} \mathrm{~d}$ and anti-IgG antiglobulin gel cards, and samples from three blood group systems: Rh, Kidd and MNSs were used. The new enhanced medium was incubated at $37^{\circ} \mathrm{C}$ for 5 minutes, low ionic strength solution (LISS) for 15 minutes, saline solution for 30 minutes, respectively. The sensitivity and specificity of blood group antibodies were then compared. The results showed that the specificity and sensitivity of the new enhanced medium incubated for 5 minutes were consistent with those of LISS and saline solution for 15 minutes and 30 minutes, respectively. The results suggest that the new enhanced medium be able to accelerate the binding of erythrocyte antibodies with antigens, reduce incubation time and optimize the detection process of indirect antiglobulin test by gel method.
\end{abstract}

Keywords: antiglobulin test, microcolumn gel test, irregular antibody

\section{INTRODUCTION}

The cross matching blood test is an item which is definitely required to be examined in the Technical Specification for Clinical Blood Transfusion. When cross matching results show incompatible, antibody screening testing must be carried out according to relevant guidelines. This ensures blood transfusion safety, improves therapeutic effects and reduces adverse reactions ${ }^{[1-4]}$. The microcolumn gel method is the most commonly used one in antiglobulin test, being the gold standard for the detection of $\mathrm{IgG}$ antibodies at present, while the indirect antiglobulin test is an effective method to detect IgG antibodies ${ }^{[5-6]}$. The enhanced solution used in this method is low ionic

*Correspondence to: Daowang Fan, Blood Group Lab, Beijing Red Cross Blood Center, Beijing, 100088, China. Tel: +86-010-82807270; E-mail: whiteflore@vip.sina.com.

Conflict of interests: The authors declare that they have no competing interests. strength solution(LISS). Using LISS cuts the incubation time to 15 minutes (conventional saline solution at $37^{\circ} \mathrm{C}$ ranges from 30 to 60 minutes), however this still seems too long for clinical diagnosis, especially in emergency situations. In this paper, a new type of enhanced medium was developed to replace LISS in the antiglobulin test with gel card. By comparing with LISS and saline solution, the sensitivity and specificity for this new method were evaluated.

\section{MATERIALS AND METHODS}

\section{Reagents and instruments}

Reagent red blood cells for irregular antibody screening(Lot.\#201711012),blood cross matching (anti-IgG) card (microcolumn gel immunoassay) (Lot.\#201703006), coombs(anti-IgG+ C3d) card (microcolumn gel immunoassay) (Lot.\#201711004), LISS(Lot.\#201708014)were all provided by Jiangsu LiBO medicine biotechnology Co., Ltd. 
China. The IgM anti-D antibodies (Lot. \#GGF1602), IgM anti-Jkb antibodies (Lot.\#BEG1601A,), IgG anti-N antibodies (Lot.\#NAC1601A), IgG anti$\mathrm{M}$ antibodies (Lot.\#NEB1601A), anti-IgG antiglobulin reagents (Lot.\#20161107)were all purchased from Millipore(U.K.) . IgG anti-Jkb antibodies(Lot.\#MJkbM075, CE), new enhanced medium(key components: $\mathrm{KH}_{2} \mathrm{PO}_{4}, \mathrm{Na}_{2} \mathrm{HPO}_{4}, \mathrm{NaCl}$, Glycine), BSA, humanized IgG anti-D serum and O type plasma were made by Jiangsu LIBO medicine biotechnology Co., Ltd., China. The Kubota centrifuge(KUBOTA Corporation, Japan), incubator and centrifuge(Jiangsu Yuanbo co., Ltd., China) were used in the above experiments.

\section{Preparation of cell suspensions from different media}

The phenotypic red blood cellsrequired for the test, including $\mathrm{D}$ antigen positive, $\mathrm{D}$ antigen negative, Jkb antigen positive, Jkb antigen negative, M antigen positive, $\mathrm{M}$ antigen negative cells, were washed once with $0.9 \% \mathrm{NaCl}$ solution. The $0.9 \%$ $\mathrm{NaCl}$ solution,LISS and new enhanced medium were used to prepare $0.8 \% \sim 1.0 \%$ cell suspensions, respectively.

\section{Specificity detection}

The blood cross matching(anti-IgG) card (microcolumn gel immunoassay), coombs (anti-IgG+C3d) card (microcolumn gel immunoassay)were marked "D+","D-", "Jkb+","Jkb-", "M+", "M-", "N+", "N-" respectively, and further labeled antibody property 'IgM/IgG, "antibody"anti-D/anti-Jkb/anti-M/anti$\mathrm{N}$ " respectively, and incubation time " $5 \mathrm{~min} / 15 \mathrm{~min} /$ 30 min." The corresponding cell suspension and antibody or plasma were added, mixed slightly, and incubated at $37{ }^{\circ} \mathrm{C}$ for 5 minutes, 15 minutes and 30 minutes. The results were observed after centrifugation.

\section{Sensitivity detection}

The blood cross matching (anti-IgG) card (microcolumn gel immunoassay) and coombs (anti$\mathrm{IgG}+\mathrm{C} 3 \mathrm{~d}$ ) card (microcolumn gel immunoassay) were marked 1 to 10 respectively, then labeled with the IgG antibody name "D/Jkb/M/N." The corresponding cell suspension and antibody or plasma were added, mixed slightly, incubated at $37^{\circ} \mathrm{C}$ for 5 minutes, 15 minutes and 30 minutes. The results were observed, the antibody titers were confirmed and the agglutination strength scores were evaluated after centrifugation.

\section{Antibody doubling dilution, titer determina- tion and agglutination strength score}

The methods followed Experimental Techniques of Transfusion Immunology and Hematology ${ }^{[6]}$. The criteria for agglutination reaction are shown in Table 1.

Table 1 Criteria for the determination of red cell agglutination

\begin{tabular}{lcc}
\hline \multicolumn{1}{c}{ Observed results } & Symbol & Score \\
\hline cell button remains in one clump & $4+$ & 12 \\
cell button dislodges into several clumps & $3+$ & 10 \\
cell button dislodges into many small clumps of equal size & $2+$ & 8 \\
$\begin{array}{l}\text { cell button dislodges into finely granular, but definite, } \\
\text { small clumps }\end{array}$ & $1+$ & 5 \\
cell button dislodges into no visible clumps & 0 & 0 \\
\hline
\end{tabular}

\section{RESULTS}

\section{IgG antibody specificity}

The specificity results of cell suspensions diluted with different media and IgG blood group antibodies in coombs (anti-IgG+C ${ }_{3} \mathrm{~d}$ ) card (microcolumn gel immunoassay) at different incubation time at $37{ }^{\circ} \mathrm{C}$ are shown in Table 2. The cell suspension diluted with different media reacted with the mixed plasma of three individuals (all without the $\mathrm{O}$ blood type irre gular antibody) and all results were negative.

\section{IgM/IgG specificity}

The specificity results of cell suspensions diluted with different media and IgM/IgG blood group antibodies in blood cross matching (anti-IgG) card (microcolumn gel immunoassay) at different incubation time at $37^{\circ} \mathrm{C}$ are shown in Table 3.

\section{IgG anti-D, anti-JKb titer and agglutination strength score}

The sensitivity results of cell suspensions diluted with different media and $\operatorname{IgG}$ antibody in coombs (anti-IgG+ $\mathrm{C}_{3} \mathrm{~d}$ ) card (microcolumn gel immunoas-

Table 2 Specific reaction of IgG anti-D and anti-Jkb in different media and different incubation time

\begin{tabular}{|c|c|c|c|c|c|c|c|c|c|c|c|c|}
\hline \multirow{3}{*}{$\begin{array}{l}\text { Incubation } \\
\text { time(min) }\end{array}$} & \multicolumn{4}{|c|}{$0.9 \% \mathrm{NaCl}$ solution } & \multicolumn{4}{|c|}{ LISS } & \multicolumn{4}{|c|}{ New enhanced medium } \\
\hline & \multicolumn{2}{|c|}{ Anti-D(IgG) } & \multicolumn{2}{|c|}{ Anti-Jkb(IgG) } & \multicolumn{2}{|c|}{ Anti-D(IgG) } & \multicolumn{2}{|c|}{ Anti-Jkb(IgG) } & \multicolumn{2}{|c|}{ Anti-D(IgG) } & \multicolumn{2}{|c|}{ Anti-Jkb(IgG) } \\
\hline & $\mathrm{D}+$ & D- & $\mathrm{Jkb}+$ & $\mathrm{Jkb}-$ & D+ & $\mathrm{D}-$ & $\mathrm{Jkb}+$ & $\overline{\mathrm{Jkb}-}$ & $\mathrm{D}+$ & $\overline{\mathrm{D}-}$ & $\mathrm{Jkb}+$ & $\mathrm{Jkb}-$ \\
\hline 5 & $1+$ & 0 & 0 & 0 & $2+$ & 0 & 0 & 0 & $3+$ & 0 & $1+$ & 0 \\
\hline 15 & $3+$ & 0 & $1+$ & 0 & $3+$ & 0 & $1+$ & 0 & $3+$ & 0 & $1+$ & 0 \\
\hline 30 & $3+$ & 0 & $1+$ & 0 & $3+$ & 0 & $1+\mathrm{s}$ & 0 & $3+$ & 0 & $1+\mathrm{s}$ & 0 \\
\hline
\end{tabular}


Table 3 Specific reactions of different antibodies in different media and different incubation time

\begin{tabular}{|c|c|c|c|c|c|}
\hline \multirow{2}{*}{ Diluent } & \multirow{2}{*}{\multicolumn{2}{|c|}{$\begin{array}{c}\text { Antibody name } \\
\text { / property }\end{array}$}} & \multicolumn{3}{|c|}{ Incubation time $(\mathrm{min})$} \\
\hline & & & \multirow{2}{*}{$\begin{array}{l}5 \\
3+\end{array}$} & \multirow{2}{*}{$\begin{array}{l}15 \\
4+\end{array}$} & \multirow{2}{*}{$\begin{array}{l}30 \\
3+\end{array}$} \\
\hline $0.9 \% \mathrm{NaCl}$ solution & Anti-D(IgM) & $\mathrm{D}+$ & & & \\
\hline & & D- & 0 & 0 & 0 \\
\hline & Anti-Jkb(IgM) & $\mathrm{Jkb}+$ & & $1+$ & $1+w$ \\
\hline & & $\mathrm{Jkb}-$ & 0 & 0 & 0 \\
\hline & Anti-M(IgG) & $\mathrm{M}+$ & $2+$ & $3+$ & $2+$ \\
\hline & & M- & 0 & 0 & 0 \\
\hline & Anti-N(IgG) & $\mathrm{N}+$ & $3+$ & $3+$ & $3+$ \\
\hline & & $\mathrm{N}-$ & 0 & 0 & 0 \\
\hline \multirow[t]{8}{*}{ LISS } & Anti-D(IgM) & $\mathrm{D}+$ & $3+$ & $4+$ & $3+$ \\
\hline & & D- & 0 & 0 & 0 \\
\hline & Anti-Jkb(IgM) & $\mathrm{Jkb}+$ & & $2+$ & $1+\mathrm{s}$ \\
\hline & & $\mathrm{Jkb}-$ & 0 & 0 & 0 \\
\hline & Anti-M(IgG) & $\mathrm{M}+$ & $3+$ & $3+$ & $3+$ \\
\hline & & M- & 0 & 0 & 0 \\
\hline & Anti-N(IgG) & $\mathrm{N}+$ & $3+$ & $4+$ & $3+$ \\
\hline & & $\mathrm{N}-$ & 0 & 0 & 0 \\
\hline \multirow[t]{8}{*}{ New enhanced medium } & Anti-D(IgM) & $\mathrm{D}+$ & $3+$ & $4+$ & $3+$ \\
\hline & & D- & 0 & 0 & 0 \\
\hline & Anti-Jkb(IgM) & $\mathrm{Jkb}+$ & $1+$ & $2+\mathrm{s}$ & $2+$ \\
\hline & & $\mathrm{Jkb}-$ & 0 & 0 & 0 \\
\hline & Anti-M(IgG) & $\mathrm{M}+$ & $4+$ & $4+$ & $3+$ \\
\hline & & M- & 0 & 0 & 0 \\
\hline & Anti-(IgG) & $\mathrm{N}+$ & $4+$ & $4+$ & $3+$ \\
\hline & & $\mathrm{N}-$ & 0 & 0 & 0 \\
\hline
\end{tabular}

say)at different incubation time and different dilution degree in $37^{\circ} \mathrm{C}$ incubator are shown in Table 4.

Table 4 Titer and score of IgG anti-D and anti-Jkb in different incubation time of three media

\begin{tabular}{lcccccc}
\hline \multirow{2}{*}{ Diluent } & \multirow{2}{*}{$\begin{array}{c}\text { Incubation } \\
\text { time(min) }\end{array}$} & \multicolumn{2}{c}{ Anti-D(IgG) } & & \multicolumn{2}{c}{ Anti-Jkb(IgG) } \\
\cline { 3 - 4 } & & titer & score & & titer & score \\
\hline 0.9\% NaCl solution & 30 & 512 & 82 & & 32 & 37 \\
LISS & 15 & 1024 & 93 & & 64 & 45 \\
New enhanced medium & 5 & 1024 & 93 & & 64 & 45 \\
& 15 & 1024 & 96 & & 64 & 45 \\
\hline
\end{tabular}

\section{IgG anti-M, anti-N titer and agglutination strength score}

The agglutination strength results of cell suspensions diluted with different media and IgG antibody in blood cross matching (anti-IgG) card (microcolumn gel immunoassay) at different incubation time and different dilution in $37^{\circ} \mathrm{C}$ incubator are shown in Table 5.

Tables 4 and 5 show that the comprehensive ranking of titer and score in the new enhanced medium was: $5 \mathrm{~min}>$ LISS $15 \mathrm{~min}>0.9 \% \mathrm{NaCl}$ solution 30 min. The titer of LISS and new reinforcement medium was similar, however the new enhanced medium had a higher score and less incubation time than LISS. Repeated experiments showed results consistent with the above phenomena.
Table 5 Titer and score of IgG anti-M and anti-N at different incubation time in three media

\begin{tabular}{lcccccc}
\hline \multirow{2}{*}{ Diluent } & \multirow{2}{*}{$\begin{array}{c}\text { Incubation } \\
\text { time }(\min )\end{array}$} & \multicolumn{2}{c}{ Anti-M(IgG) } & & \multicolumn{2}{c}{ Anti-N(IgG) } \\
\cline { 3 - 4 } & & titer & score & & titer & score \\
\hline 0.9\% NaCl solution & 30 & 32 & 34 & & 128 & 63 \\
LISS & 15 & 32 & 50 & & 256 & 71 \\
New enhanced medium & 5 & 64 & 55 & & 256 & 83 \\
\hline
\end{tabular}

\section{DISCUSSION}

The antiglobulin test is used to detect clinically significant irregular antibodies. Antiglobulin antibodies act as a bridge to connect specific antibodies bound to erythrocyte surface antigen and agglutinate erythrocytes. The traditional tube method is limited in its clinical application because it requires manual operation and incubation time as long as 30 to 60 minutes. Also the red blood cells need to be washed three times after incubation. At present, the most commonly used method is the microcolumn gel antiglobulin method. Erythrocytes and serum are added to the reaction cavity of the microcolumn gel containing antiglobulin reagent, with results observed directly by centrifugation after incubation ${ }^{[7]}$. The incubation time can be shortened to 15 minutes by using LISS as the enhancement fluid ${ }^{[8-10]}$, however the incubation time is still long which affects the efficiency of clinical pre-transfusion test. Therefore making it difficult to screen for antibodies and crossmatching in a clinical emergency.

The results of this study show that the new enhanced medium can be used to detect not only IgG antibodies but also IgM antibodies when incubated at $37{ }^{\circ} \mathrm{C}$ with the antiglobulin card. The antibody specificity test showed the results of incubation of the new enhanced medium for 5 and 15 minutes were consistent with those of LISS for 15 minutes and $0.9 \% \mathrm{NaCl}$ solution for 30 minutes. The antibody sensitivity test showed the antibody titer of 5 minutes incubated with new enhanced medium was slightly different from that of 15 minutes, and the agglutination strength score of the new enhanced medium for 5 minutes was higher than that of LISS for 15 minutes and $0.9 \% \mathrm{NaCl}$ solution for 30 minutes. These results suggest that the new enhanced medium developed and prepared in this paper can reduce the incubation time. Under the premise of ensuring sensitivity and specificity, the incubation time can be shortened to 5 minutes at $37{ }^{\circ} \mathrm{C}$ for pre-transfusion detection, so the appropriate therapeutic blood can be selected in a shorter time.

There may be three reasons why the new enhanced medium can shorten the incubation time at $37^{\circ} \mathrm{C}$ 
while still ensuring specificity and sensitivity. One reason is that the new enhancer contains BSA, which has positive charges, can neutralize the negative charge on the cell surface, reduce the surface charge of red blood cells, reduce the repulsive force between red blood cells, and shorten the distance between red blood cells. Secondly, BSA also has strong hydrophilicity, which can destroy the hydrophilic layer on the surface of red blood cells and reduce the spatial rejection effect when antibodies bind to red blood cell antigen. Thirdly, the new enhanced medium is a kind of low-ion liquid, which is able to provide a low ion environment that can increase the chance of collision between positive and negative charged antibodies to produce a specific combination of antigenantibody complexes, promote the binding efficiency of antibody and antigen, and shorten the binding time of antigen and antibody.The above three aspects can accelerate the binding of antibodies to the corresponding antigens on red blood cells, at the same time, enhance the reaction intensity between antigens and antibodies (especially in $\mathrm{IgG}$ ) and further reduce the incubation time and improve the agglutination effect.

\section{Acknowledgments and funding}

This work was supported by grant from Special Project for Transformation of Scientific and Technological Achievements of Jiangsu Province (No. BA2017047).

\section{References}

[1] Ministry of Health P.R.C. Technical Specification for Clinical Blood Transfusion[Z].(in Chinese)
[2] Hong S, Wang YS, Shen ZY, National guide to clinical laboratory procedures[M]. Beijing:People's Medical Publishing House, 2014:127-138

[3] Zhou Z, Dan X, Ling S, et al. The progress in pretransfusion test technique research[J]. Asia-Pacific Journal of Blood Types and Genes, 2017,1(3):7-12

[4] Ma QZ, Yang ZZ, Zou MX, et al. Comparison of the application of condensed amine method and microcolumn gel method for detection of irregular antibodies[J]. Laboratory And Laboratory Medicine, 2018, 36(4):619-621

[5] Yang SM, Yang CL, Hong BY, et al. Effect of low Ionic strength solution and polyethylene glycol on sensitivity of indirect anti human globulin test[J]. PLA Medical Journal,(in Chinese), 1995, 20(5):371-373

[6] Liu JH, JiongcaiLan, Yuan ZQ, et al. Experimental techniques of transfusion immunology and hematology[M]. Beijing:People's Medical Publishing House, (in Chinese),2011:63-65

[7] Yong L, Ma XY. Practical blood immunology blood group theory and experimental techniques[M]. Beijing:Science Press, (in Chinese), 2006:566-569

[8] Zhou SR, Deng AY, Wu CL, et al. Application of low Ionic strength solution in blood transfusion related tests[J]. International Journal of Laboratory Medicine, (in Chinese),2013,34(22):3063-3064

[9] Deng AY, Zhou SR, Wu CL, et al. Application of low Ionic strength solution in antiglobulin test[J]. Laboratory Medicine and Clinic,(in Chinese), 2013, 10(23):3203-3205

[10] Zhong QL. Evaluation and analysis of the application value of low Ionic strength solution in blood transfusion related test[J]. The Journal of Medical Theory and Practice, (in Chinese),2016, 29(20):3545-3546

(Received 14 October 2018, Revised 09 November 2018, Accepted 21 November 2018) 